\title{
Temperature effect on performance of nanoparticle/surfactant flooding in enhanced heavy oil recovery
}

\author{
Sajjad Mahmoudi ${ }^{1} \cdot$ Arezou Jafari $^{1} \cdot$ Soheila Javadian ${ }^{2}$
}

Received: 17 July 2018 / Published online: 25 September 2019

(c) The Author(s) 2019

\begin{abstract}
Recently, nanoparticles have been used along with surfactants for enhancing oil recovery. Although the recent studies show that oil recovery is enhanced using nanoparticle/surfactant solutions, some effective parameters and mechanisms involved in the oil recovery have not yet been investigated. Therefore, the temperature effect on the stability of nanoparticle/surfactant solutions and ultimate oil recovery has been studied in this work, and the optimal concentrations of both $\mathrm{SiO}_{2}$ nanoparticle and surfactant (sodium dodecyl sulfate) have been determined by the Central Composite Design method. In addition, the simultaneous effects of parameters and their interactions have been investigated. Study of the stability of the injected solutions indicates that the nanoparticle concentration is the most important factor affecting the solution stability. The surfactant makes the solution more stable if used in appropriate concentrations below the CMC. According to the micromodel flooding results, the most effective factor for enhancing oil recovery is temperature compared to the nanoparticle and surfactant concentrations. Therefore, in floodings with higher porous medium temperature, the oil viscosity reduction is considerable, and more oil is recovered. In addition, the surfactant concentration plays a more effective role in reservoirs with higher temperatures. In other words, at a surfactant concentration of $250 \mathrm{ppm}$, the ultimate oil recovery is improved about $20 \%$ with a temperature increase of $20^{\circ} \mathrm{C}$. However, when the surfactant concentration is equal to $750 \mathrm{ppm}$, the temperature increase enhances the ultimate oil recovery by only about $7 \%$. Finally, the nanoparticle and surfactant optimum concentrations determined by Design-Expert software were equal to 46 and 159 ppm, respectively. It is worthy to note that obtained results are validated by the confirmation test.
\end{abstract}

Keywords Enhanced heavy oil recovery $\cdot$ Nanoparticle $\cdot$ Surfactant $\cdot$ Temperature $\cdot$ High salinity brine $\cdot$ Stability $\cdot$ Micromodel $\cdot$ Experimental design

\section{Introduction}

The natural power of oil reservoir production, referred to as the primary recovery, is known to decrease on a daily basis, so the oil production also decreases. This is not economically feasible as the recovered oil is generally less than $30 \%$ of the original oil in place. After the primary recovery, water

Edited by Yan-Hua Sun

Arezou Jafari

ajafari@modares.ac.ir

1 Department of Petroleum Engineering, Faculty of Chemical Engineering, Tarbiat Modares University, Tehran, Iran

2 Department of Physical Chemistry, Faculty of Basic Science, Tarbiat Modares University, P.O. Box 14115-175, Tehran, Iran flooding is usually used to increase oil recovery as the secondary recovery. Water flooding can enhance oil recovery to $50 \%$. In heavy oil reservoirs, not only is the primary recovery usually less than $20 \%$, but the efficiency of water flooding is also lower than $10 \%$ due to the big difference between heavy oil and water mobility (Mai et al. 2009). Therefore, using a tertiary recovery method such as chemical EOR may be useful.

One of the chemical EOR methods is the injection of surfactants into oil reservoirs. Since the oil price has been generally increasing, the application of surfactants has gained great attention (Iglauer et al. 2010). Surfactants reduce oil/water interfacial tension (IFT) and alter reservoir rock wettability (Vladimir and Eduardo 2010). Surfactants can increase the capillary number by decreasing the capillary force responsible for trapping oil, and thus more oil can be recovered. Many studies have focused on surfactant flooding 
(Howe et al. 2015; Yadali Jamaloei et al. 2011; Kianinejad et al. 2013, 2014; Yadali Jamaloei and Kharrat 2009; Lohne and Fjelde 2012; Daoshan et al. 2004; Seethepalli et al. 2004; Wu et al. 2006; Pillai et al. 2018). In addition, laboratory results indicate that nanoparticles can reasonably recover more of the trapped oil (Bera and Belhaj 2016). In fact, oil/water IFT, rock wettability, and/or oil viscosity can be improved by nanoparticles (Alomair et al. 2014; Munshi et al. 2008; Ogolo et al. 2012; Torsater et al. 2012; Esmaeilzadeh et al. 2014; Maghzi et al. 2010; Hamedi et al. 2010; Hendraningrat et al. 2013).

Lately, simultaneous application of nanoparticles and surfactants for improving oil efficiency has been investigated. Zargartalebi et al. (2014, 2015) have concluded that IFT will diminish more when nanoparticles are mixed with surfactant solutions and the absorption of surfactant molecules on the rock is generally reduced. Therefore, oil recovery is increased by a considerable amount. Similar results regarding decreased surfactant absorption have been obtained by Ahmadi and Shadizadeh (2013). Suleimanov et al. (2011) have reported a higher reduction in surface tension by non-ferrous metal nanoparticles. Ma et al. (2008) have also reported that the nanoparticle/surfactant solution can decrease surface tension. Sun et al. $(2014,2015)$ have indicated that $\mathrm{SiO}_{2} / \mathrm{SDS}$ stabilized foams are more stable and recover more oil than those stabilized just by SDS. Pei et al. (2015) have shown that silica nanoparticles mixed with hexadecyltrimethylammoniumbromide (CTAB, a cationic surfactant) improve emulsion stability and significantly increase oil recovery. Qiu (2010) has also reported that the addition of nanoparticles to the surfactant-stabilized emulsion decreases in situ oil viscosity, resulting in a favorable mobility ratio. Lan et al. (2007) have investigated the synergistic effect of silica nanoparticles and CTAB on the stabilization of $\mathrm{O} / \mathrm{W}$ emulsions and concluded that nanoparticles can improve the emulsion stability with the appropriate concentration of CTAB. Wu et al. (2017) have indicated that silica nanoparticles can reduce the static and dynamic SDS surfactant absorption and thus enhance oil recovery. (Nwidee et al. 2017) have concluded that the nanoparticle/ surfactant system can improve the wettability of the system and favors enhancing oil recovery. Maurya and Mandal (2018) have indicated that nanoparticles make the system more stable. They have studied the synergistic effect of surfactants and nanoparticles on physicochemical properties to improve oil recovery. Kumar and Mandal (2018) have also shown that simultaneous use of nanoparticles and surfactant can improve physicochemical properties of emulsion and enhance oil recovery.

Some researchers have investigated the simultaneous effect of nanoparticles and surfactants, but some important parameters such as the effect of reservoir temperature on the results have not yet been carefully investigated. Therefore, in this research, the effects of reservoir temperature on solution stability and ultimate oil recovery have been studied and the optimum concentrations of silica nanoparticle and SDS surfactant have been determined by CCD. In addition, the simultaneous effects of parameters and their interactions have been studied for the first time. Many micromodel floodings have been performed for this purpose. In addition, viscosity, wettability and interfacial tension of the injected solutions have been measured to study the corresponding mechanisms and interactions.

\section{Materials and methods}

\subsection{Materials}

Sodium dodecyl sulfate (SDS) with a purity of $95 \mathrm{wt} \%$ was supplied by Merck Chemical Co. (Germany). The critical micelle concentration (CMC) of SDS in distilled water was $2393 \mathrm{ppm}$ at $25^{\circ} \mathrm{C}$ (Cifuentes et al. 1997). Hydrophilic silica nanoparticle $\left(\mathrm{SiO}_{2}\right)$ with a purity of $98 \mathrm{wt} \%$ supplied by US-Nano was used. The average particle size and the specific surface area of $\mathrm{SiO}_{2}$ nanoparticles were 11-14 nm and $600-785 \mathrm{~m}^{2} / \mathrm{g}$, respectively. The oil used was collected from an Iranian oil reservoir. It has a density of $0.94 \mathrm{~g} / \mathrm{cm}^{3}$ at $25^{\circ} \mathrm{C}$ and an oil API gravity of $12.5^{\circ}$. The oil viscosity was $3580 \mathrm{cP}$ at $25^{\circ} \mathrm{C}$, measured with a Brookfield viscometer. $\mathrm{NaCl}$ (purity $99.5 \mathrm{wt} \%$ ) supplied by Tetra-Chem (Canada) was used to prepare all solutions at a concentration of $3.5 \mathrm{wt} \%$. In this salinity, the CMC of the SDS solution was about 288 ppm (Javadian et al. 2013). Toluene and distilled water were used to clean the micromodel.

\subsection{Experimental procedure}

\subsubsection{Solution preparation and stability investigation}

Several aqueous solutions were made with a constant salinity of $3.5 \mathrm{wt} \%(35,000 \mathrm{ppm})$. After adding $\mathrm{NaCl}$ to the solutions, the nanoparticles were added, and the solutions were then stirred for $20 \mathrm{~min}$ at a rate of $300 \mathrm{rpm}$. Solutions were dispersed ultrasonically ( $400 \mathrm{~W}, 20 \mathrm{kHz}$ ) for $30 \mathrm{~min}$. The surfactant was then added to the solution, and stirring was continued for $10 \mathrm{~min}$.

UV/VIS spectrophotometry is a convenient approach to characterize the stability of colloids quantitatively. Therefore, in this study, the light transmission of all the samples was measured with an Optizen 3220 UV spectrophotometer (Korea). In addition, the solutions were photographed simultaneously with light transmission measurements. It should be noted that the solution stabilities were investigated at the 
temperature at which the micromodel flooding tests were conducted.

\subsubsection{Micromodel test}

A schematic diagram of the micromodel setup utilized in this study is shown in Fig. 1a. The heterogeneous micromodel designed with CorelDraw software was made using laser technology, based on the thin section of a real porous medium (Mohammadi et al. 2013). A schematic representation and the properties of the micromodel pattern are presented in Fig. 1b and Table 1, respectively. In order to alter the wettability of the micromodel to strongly oil-wet, the following procedure was applied: (1) rinsing the micromodel thoroughly with sodium hydroxide for $1 \mathrm{~h}$; (2) rinsing the micromodel thoroughly with distilled water to remove all residues and then drying it in an oven at $200{ }^{\circ} \mathrm{C}$ for at least $15 \mathrm{~min}$; (3) preparing a dilute solution of $2 \%$ trichloromethylsilane (TCMS) and 98\% dehydrated toluene; (4) saturating the micromodel with the dilute solution for at least 5 min; (5) rinsing the micromodel with methanol to remove excess siliconizing fluid; (6) drying the micromodel in an oven at $100{ }^{\circ} \mathrm{C}$ for $1 \mathrm{~h}$ to cure the silicone coating (Emami Meybodi et al. 2011).

Before each experiment, the micromodel was cleaned with toluene and distilled water. The micromodel was then evacuated using a vacuum pump, and the micromodel wettability was altered to oil-wet. Next, the micromodel was fully saturated with oil in the absence of connate water saturation. The displacement process was then started at a fixed rate of $0.0008 \mathrm{~mL} / \mathrm{min}$ at water bath temperature and ambient pressure. During each test, images were taken every minute by a Canon 7D EOS camera to calculate the residual oil saturation or ultimate oil recovery factor through image processing techniques using Photoshop software (Adobe Photoshop CS6). Using the images, the pixels of the initial oil in the micromodel were calculated prior to and following flooding.
Table 1 Properties of the micromodel

\begin{tabular}{llllll}
\hline $\begin{array}{l}\text { Length, } \\
\mathrm{cm}\end{array}$ & $\begin{array}{l}\text { Width, } \\
\mathrm{cm}\end{array}$ & $\begin{array}{l}\text { Average } \\
\text { depth, } \mathrm{cm}\end{array}$ & $\begin{array}{l}\text { Porosity, } \\
\%\end{array}$ & $\begin{array}{l}\text { Pore } \\
\text { volume, } \\
\mathrm{mL}\end{array}$ & $\begin{array}{l}\text { Perme- } \\
\text { ability, } \\
\mathrm{mD}\end{array}$ \\
\hline 6 & 6 & 0.006 & 38 & 0.22 & 890 \\
\hline
\end{tabular}

Therefore, the ultimate oil recoveries could be measured by subtracting the pixels of initial oil from those of the remaining oil and dividing the calculated pixels by the initial oil pixels. It is necessary to note that the micromodel was horizontally placed during the tests.

\subsubsection{Viscosity measurement}

The main physical property of fluids such as aqueous solutions is their viscosity. The viscosity of the solutions was determined using a Brookfield viscometer at $25^{\circ} \mathrm{C}$. Since micromodel flooding tests were conducted at temperatures above $25{ }^{\circ} \mathrm{C}$, the oil viscosity was measured at flooding temperatures.

\subsubsection{Interfacial tension measurement}

The interfacial tensions between the injected fluids and oil were measured at $25^{\circ} \mathrm{C}$ using a Lauda TE3 tensiometer. Since the tensiometer used in this work could not directly calculate the IFTs (because of the quite small IFTs), IFTs were measured by the maximum force, $F$, determined by the device, using the following equation:

$\gamma=\frac{F}{P \cos \theta} f$

where $\gamma$ is the IFT, $\mathrm{mN} / \mathrm{m} ; F$ is the maximum measured force, $\mathrm{mg} ; P$ is the perimeter of the three-phase contact line, $\mathrm{mm} ; \theta$ is the contact angle measured for the liquid meniscus
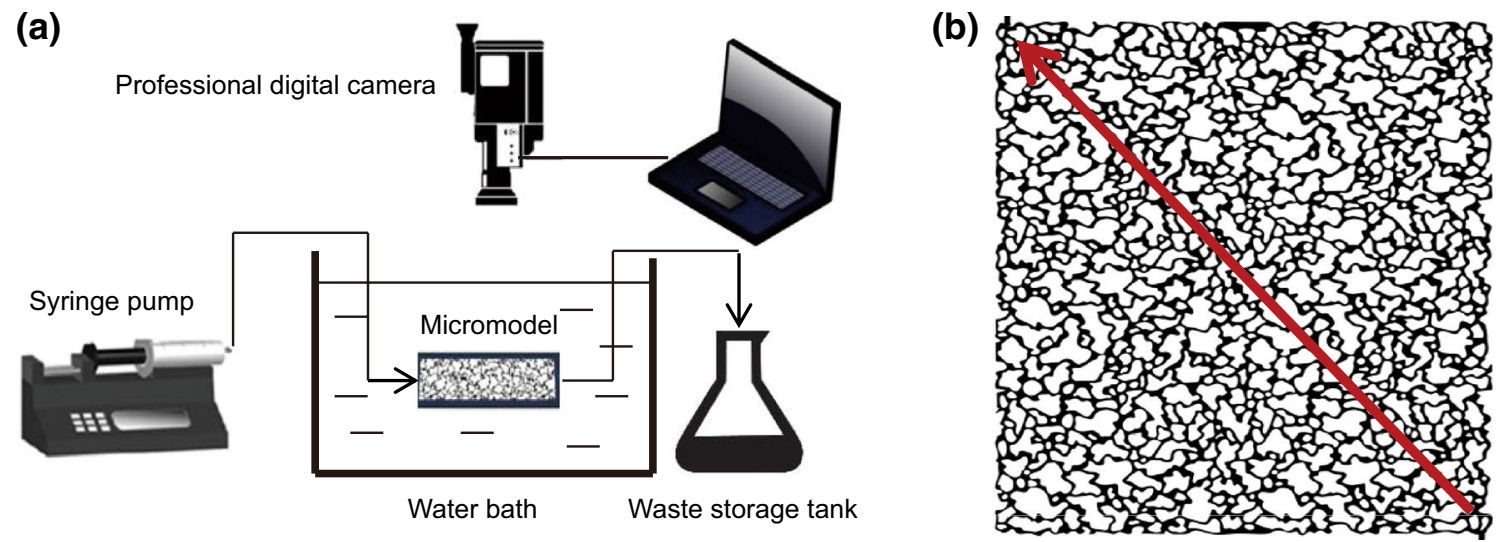

Fig. 1 a Schematic of the micromodel setup. b Schematic of the porous medium (the arrow shows flow direction) 
in contact with the object surface, ${ }^{\circ}$; and $f$ is the correction factor calculated by the following equation

$f=0.725+\left(\frac{9.075 \times 10^{-4} F}{\pi^{3} \Delta \rho g R^{3}}-\frac{1.679 r}{R}+0.04534\right)^{1 / 2}$

where $\Delta \rho$ is the difference in fluid density, $\mathrm{g} / \mathrm{cm}^{3} ; R$ is the ring radius, $\mathrm{mm}$; and $r$ is the ring wire radius, $\mathrm{mm}$ (Drelich et al. 2002). A test was carried out at $65^{\circ} \mathrm{C}$ to study the temperature effect on IFT; due to the negligible effect on the measured IFT, other tests were performed at ambient temperature $\left(25^{\circ} \mathrm{C}\right)$.

\subsubsection{Contact angle measurement}

To compare the effects of nanoparticles, surfactant and nanoparticle/surfactant solutions on the contact angle, it was measured using a handheld microscope with $500 \times$ magnification. Having been altered to oil-wet, a glass identical to the micromodel glass was aged in the prepared aqueous solutions for $30 \mathrm{~min}$ at $25^{\circ} \mathrm{C}$. The contact angle changes of water drops on the glass before and after aging were then measured with a handheld microscope. Figure 2 shows the setup for measuring the contact angle.

\subsubsection{Zeta potential measurement}

In order to investigate how the surface charges on nanoparticles change upon adding the salt and/or surfactant to the solutions, zeta potentials of five solutions presented in Table 2 were measured by a Zetasizer Nano device from Malvern Panalytical (UK). Since the device could not measure the zeta potential at a $\mathrm{NaCl}$ concentration of $3.5 \mathrm{wt} \%$
Table 2 Zeta potential measurements

\begin{tabular}{lllll}
\hline $\begin{array}{l}\text { Solution } \\
\text { name }\end{array}$ & $\begin{array}{l}\text { NaCl concen- } \\
\text { tration, wt } \%\end{array}$ & $\begin{array}{l}\mathrm{SiO}_{2} \text { concen- } \\
\text { tration, ppm }\end{array}$ & $\begin{array}{l}\text { SDS concen- } \\
\text { tration, ppm }\end{array}$ & $\begin{array}{l}\text { Zeta } \\
\text { potential, } \\
\mathrm{mV}\end{array}$ \\
\hline$\alpha$ & 0 & 500 & 0 & -20.4 \\
$\beta$ & 1.5 & 500 & 0 & -6.79 \\
$\gamma$ & 1.5 & 500 & 250 & -14.3 \\
$\eta$ & 1.5 & 500 & 500 & -13.6 \\
$\lambda$ & 1.5 & 500 & 750 & -15.0 \\
\hline
\end{tabular}

(because of high electrical conductivity of solutions), the tests were performed at a salinity of $1.5 \mathrm{wt} \%$ at $25^{\circ} \mathrm{C}$, taking into consideration the fact that the surface charge variations were important rather than the absolute values.

\subsubsection{Experimental design}

In this study, experimental design was performed by response surface methodology (RSM) to assess the relationship between responses, solution stability and ultimate oil recovery, and operating variables, bath temperature (or temperature in brief) at which the floodings were carried out, nanoparticle concentration and surfactant concentration. In addition, the operating variables were optimized to predict the best value of the responses. Central Composite Design (CCD), the most popular RSM, was utilized in this work (Gunnasegaran et al. 2015). Therefore, to study the influence of the variables (factors) on the responses, a CCD based on five levels was used. Design-Expert software (version 7.0.0) was used to process the data (Arshadi and Mousavi 2015). Factors and their levels are shown in Table 3.

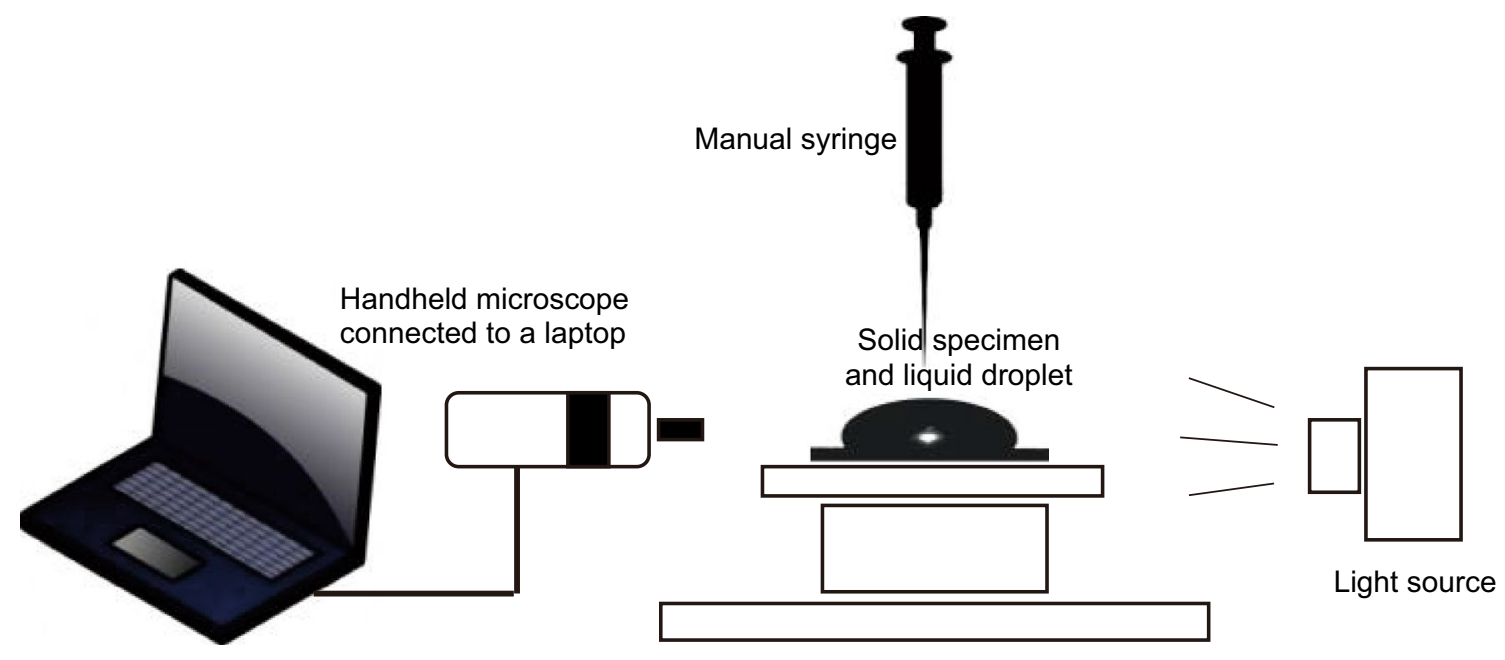

Fig. 2 Schematic of the contact angle setup 
Table 3 Factors and their levels

\begin{tabular}{llccrrr}
\hline Factors & Units & Level 1 & Level 2 & Level 3 & Level 4 & Level 5 \\
\hline Temperature & ${ }^{\circ} \mathrm{C}$ & 25 & 35 & 45 & 55 & 65 \\
Nanoparticle concentration & $\mathrm{ppm}$ & 0 & 250 & 500 & 750 & 1000 \\
Surfactant concentration & $\mathrm{ppm}$ & 0 & 250 & 500 & 750 & 1000 \\
\hline
\end{tabular}

Table 4 Tests performed under different conditions and obtained responses

\begin{tabular}{|c|c|c|c|c|c|}
\hline $\begin{array}{l}\text { Test No. } \\
\text { (or solution) }\end{array}$ & $\begin{array}{l}\text { Factor } A \text { : } \\
\text { temperature, }{ }^{\circ} \mathrm{C}\end{array}$ & $\begin{array}{l}\text { Factor } B: \mathrm{SiO}_{2} \\
\text { concentration, ppm }\end{array}$ & $\begin{array}{l}\text { Factor } C: \text { SDS } \\
\text { concentration, ppm }\end{array}$ & $\begin{array}{l}\text { Response 1: } \\
\text { stability, days }\end{array}$ & $\begin{array}{l}\text { Response 2: ultimate } \\
\text { recovery, \% }\end{array}$ \\
\hline 1 & 35 & 250 & 250 & 10 & 25.20 \\
\hline 2 & 55 & 250 & 250 & 10 & 44.76 \\
\hline 3 & 35 & 750 & 250 & 4 & 18.60 \\
\hline 4 & 55 & 750 & 250 & 1 & 44.97 \\
\hline 5 & 35 & 250 & 750 & 13 & 23.13 \\
\hline 6 & 55 & 250 & 750 & 9 & 31.04 \\
\hline 7 & 35 & 750 & 750 & 6 & 18.02 \\
\hline 8 & 55 & 750 & 750 & 1 & 25.49 \\
\hline 9 & 25 & 500 & 500 & 8 & 17.69 \\
\hline 10 & 65 & 500 & 500 & 1 & 39.35 \\
\hline 11 & 45 & 0 & 500 & $20^{\mathrm{a}}$ & 31.44 \\
\hline 12 & 45 & 1000 & 500 & 1 & 33.60 \\
\hline 13 & 45 & 500 & 0 & 3 & 15.52 \\
\hline 14 & 45 & 500 & 1000 & 3 & 29.32 \\
\hline 15 & 45 & 500 & 500 & 3 & 32.55 \\
\hline 16 & 45 & 500 & 500 & 3 & 31.16 \\
\hline 17 & 45 & 500 & 500 & 3 & 34.69 \\
\hline 18 & 45 & 500 & 500 & 3 & 35.47 \\
\hline 19 & 65 & 45.81 & 158.59 & 20 & 42.12 \\
\hline 20 & 65 & 133.67 & 192.85 & - & 44.17 \\
\hline 21 & 65 & 0 & 0 & - & 25.50 \\
\hline
\end{tabular}

${ }^{\text {a }}$ The stability of solution 11 containing only SDS was considered 20 days because the stability investigation was done for 20 days

\subsubsection{Sandpack flood test}

In order to compare the micromodel flooding results with those of core flooding, a sandpack flood test was conducted (sandpack: $20 \mathrm{~cm}$ length and $2.5 \mathrm{~cm}$ diameter). The sandpack flood was carried out under the same conditions $\left(45^{\circ} \mathrm{C}\right.$ and ambient pressure) and concentrations as the tests 15-18 of Table 4 known as center points because they were conducted four times in the micromodel floodings. The experimental steps of sandpack flooding were as follows: First, the heavy oil was injected into the sandpack. The solution with the concentration of the center points was then injected into the sandpack at a flow rate of $0.5 \mathrm{~mL} / \mathrm{min}$ until the oil production became negligible (oil cut $<2 \%$ ).

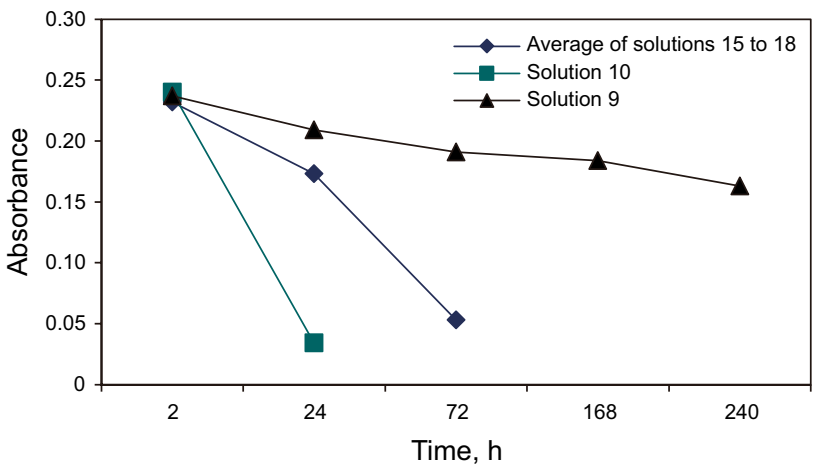

Fig. 3 Light absorbance measurements for solutions 9, 10 and average of solutions $15-18$ 


\section{Results and discussion}

\subsection{Stability analysis}

The results of the experiments performed under different conditions and the responses obtained are presented in Table 4. Light absorbance results and pictures of all solutions were monitored. Figure 3 shows the light absorbance values of tests 9, 10 and the average light absorbance values of solutions 15-18 (the average light absorbance values of solutions $15,16,17$ and 18 were used because they were the center point tests and the test setting was similar for all of them). Figure 4 shows the qualitative investigation of solutions 9, 10 and 15 and their pictures. Observation of Figs. 3 and 4 shows that the solutions were unstable when the light absorbance decreased strongly.

\subsubsection{Temperature effect on solution stability}

According to DLVO theory, two forces are effective in the coagulation of the dispersed particles; namely, the attractive van der Waals and repulsive electrostatic double layer forces (Butt et al. 2004). Silica particles have negative surface charges in water (solution $\alpha$ in Table 2) due to the oxygens and thus the repulsive electrostatic forces decrease the effect of attractive van der Waals forces (Fig. 5a). The addition of $\mathrm{NaCl}$ caused the negative surface charges on the particles to decrease (solution $\beta$ in Table 2) because the particles attracted $\mathrm{Na}^{+}$cations in the $\mathrm{NaCl}$ salt. Therefore, the solution stability reduced (Fig. 5b). However, adding SDS anionic surfactant enhances the stability. When the SDS surfactant dissolves in water, $\mathrm{Na}^{+}$cations in SDS structures are added to aqueous solutions and the surfactant head has a negative surface charge. Therefore, the heads of the surfactants are attached to the silica particles with less negative surface charge due to the attraction of $\mathrm{Na}^{+}$cations and hence the surface charges of particles become more negative (solutions $\gamma, \eta$ and $\lambda$ in Table 2). Afterward, the hydrophobic tails of surfactants connected to the particles come in contact with the tails of the surfactants present in the aqueous phase. Consequently, a hydrophobic layer is formed near the silica particle and the solution stability increases as a result (Fig. 5c).
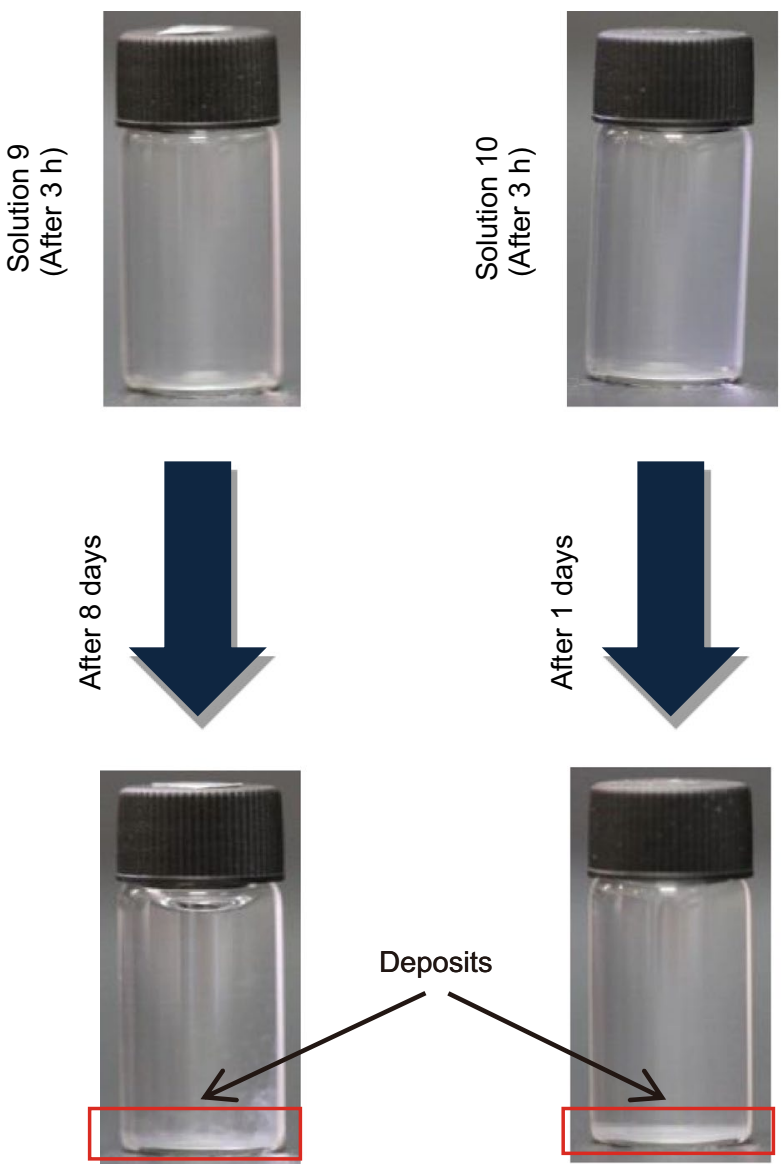
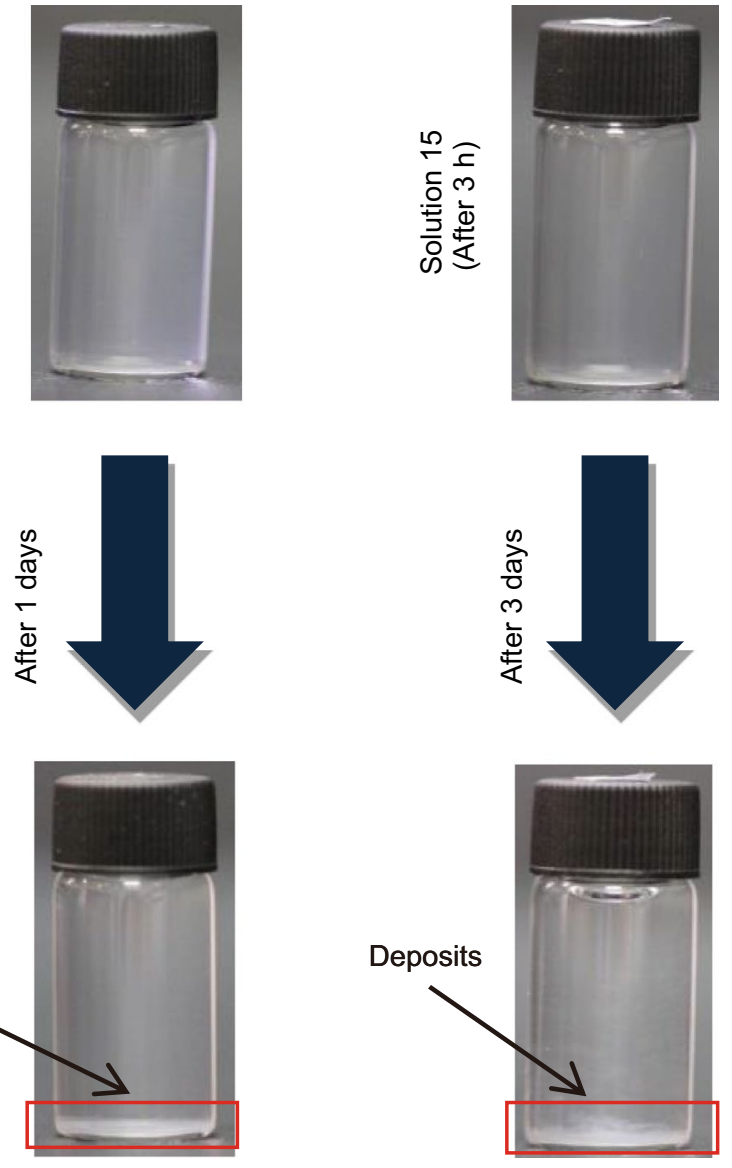

Fig. 4 Pictures of solutions 9, 10 and 15 before and after nanoparticle deposition 


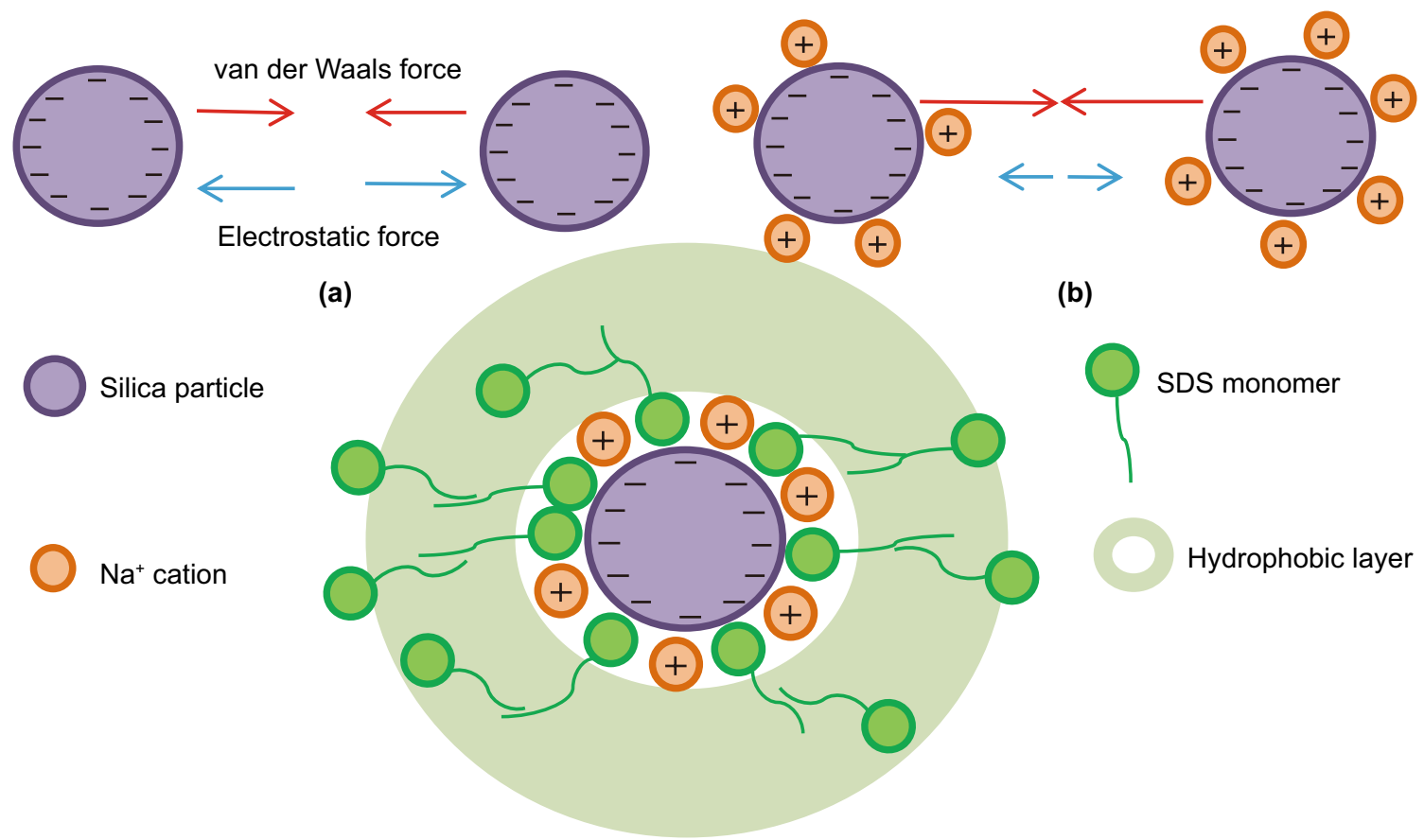

(c)

Fig. 5 Schematic of a silica particle in aqueous solutions without $\mathrm{NaCl}$ and $\mathrm{SDS}$ (a), with $\mathrm{NaCl}$ (b); and with $\mathrm{NaCl}$ and $\mathrm{SDS}$ (c)

The comparison of four pairs of tests $(3,4),(5,6),(7,8)$, $(9,10)$ in which nanoparticle and surfactant concentrations were the same shows that an increase in temperature reduces the solution stability since the kinetic energy of particles increases as the temperature increases. Therefore, the particle collisions are enhanced and larger particles are formed because of van der Waals forces. The solution then becomes unstable due to the increased gravity force effect. However, this trend was not observed in one pair of the tests $(1,2)$. Despite a temperature rise of $20^{\circ} \mathrm{C}$, the stabilities of tests 1 and 2 were equal to 10 days. The point was that in tests $(3,4),(5,6),(7,8),(9,10)$, nanoparticle and/or surfactant concentrations were higher than those of nanoparticle and/ or surfactant of tests $(1,2)$. On the one hand, increasing the nanoparticle concentration increases particle collisions and decreases the stability of solutions. On the other hand, when the surfactant concentration exceeds CMC, micelles are formed, and the surfactant monomers attached to the silica particles prefer to join the formed micelles and consequently the solutions become unstable. This process was facilitated by temperature increase, but it did not occur in the tests (1, 2) because the surfactant concentration was lower than the CMC of the surfactant. The comparison of tests 2 and 6 shows that the stability of solution 2 was one day more than that of solution 6 although the surfactant weight percent of the solution 6 was three times higher than that of solution 2 . In addition, the stability of solution 14 containing $1000 \mathrm{ppm}$ SDS was equal to that of solution 13 , which contained no surfactant. These two abnormal changes in stability could be explained considering the fact that the surfactant concentration in solutions 6 and 14 was high enough to form micelles and thus the monomers attached to the silica particles immigrate to join the micelles while the temperature rise helps the monomers detach the particles.

\subsubsection{Statistical analysis}

To find the significant terms and identify factors and their interaction importance, the results were statistically analyzed. The analysis of variance (ANOVA) suggested a quadratic model for response 1 (stability). Table 5 illustrates ANOVA for the stability. As the ANOVA shows, the model was found to be significant for the stability response in $95 \%$ confidence level by $p<0.05$. The high value of $R^{2}$ (about 0.96 ) confirms that the model is capable of representing the experimental systems. A larger $F$ value for a factor indicates that the factor has a significant effect on the response (Arshadi and Mousavi 2015). However, a lower $p$ value for a factor indicates that the factor is more effective on the response. Considering the $p$ values, the nanoparticle concentration (factor $B$ ) and the temperature (factor $A$ ) were the most effective factors on solution stability. The suggested model in terms of actual factors is presented by the following equation: 
Table 5 ANOVA for stability response

\begin{tabular}{|c|c|c|c|c|c|}
\hline Source & Sum of squares $R^{2}$ & $\mathrm{df}^{\mathrm{a}}$ & Mean square & $F$ value & $p$ value \\
\hline Model & 430.65 & 9 & 47.85 & 24.94 & $<0.0001$ \\
\hline$A$ : temperature & 42.25 & 1 & 42.25 & 22.02 & 0.0016 \\
\hline$B$ : nanoparticle concentration & 289 & 1 & 289 & 150.62 & $<0.0001$ \\
\hline$C:$ surfactant concentration & 1 & 1 & 1 & 0.52 & 0.4909 \\
\hline$A B$ & 2 & 1 & 2 & 1.04 & 0.3372 \\
\hline$A C$ & 4.5 & 1 & 4.5 & 2.35 & 0.1642 \\
\hline$B C$ & 0 & 1 & 0 & 0 & 1 \\
\hline$A^{2}$ & 4.92 & 1 & 4.92 & 2.57 & 0.1479 \\
\hline$B^{2}$ & 85.1 & 1 & 85.1 & 44.35 & 0.0002 \\
\hline$C^{2}$ & 0.22 & 1 & 0.22 & 0.11 & 0.7446 \\
\hline Residual & 15.35 & 8 & 1.92 & & \\
\hline Lack of fit & 15.35 & 5 & 3.07 & & \\
\hline Pure error & 0 & 3 & 0 & & \\
\hline Cor total & 446 & 17 & & & \\
\hline
\end{tabular}

${ }^{\text {a }}$ The degrees of freedom (df) in the source
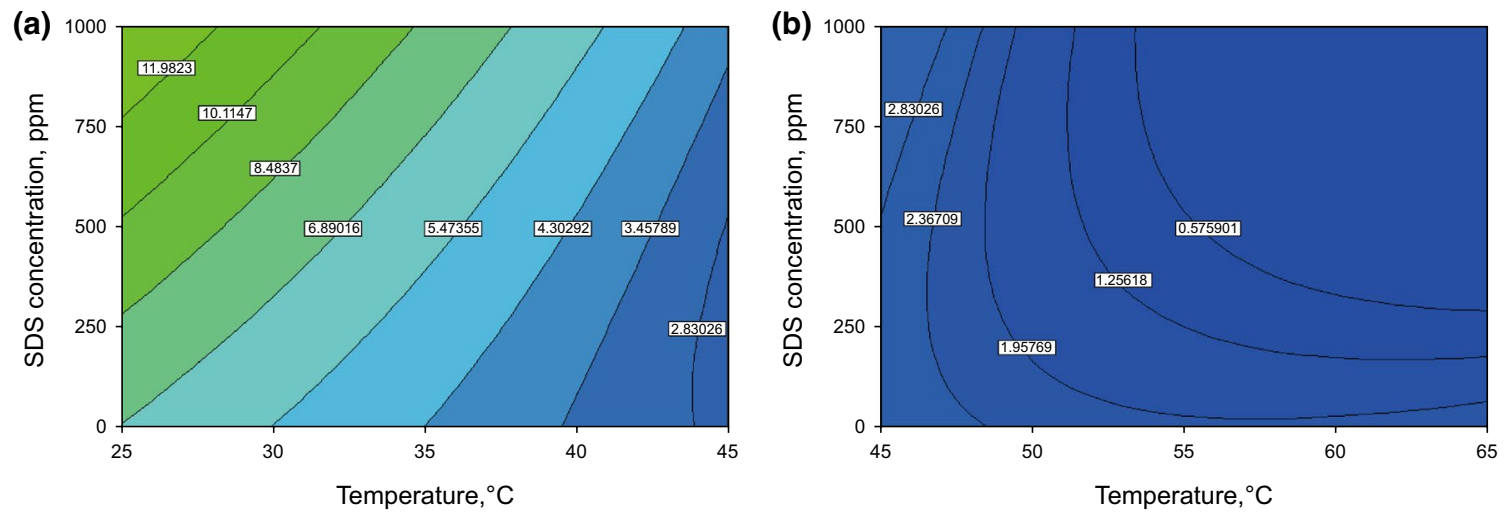

Fig. 6 SDS concentration versus temperature at $1000 \mathrm{ppm}$ silica nanoparticles, the contours show solution stability (day). a $25-45{ }^{\circ} \mathrm{C}$. b $45-65{ }^{\circ} \mathrm{C}$

$$
\begin{aligned}
\text { Stability }= & 25.38125-0.34 A-0.0396 B+0.0129 C \\
& -2.0 \times 10^{-4} A B-3.0 \times 10^{-4} A C \\
& +4.75 \times 10^{-3} A^{2}+3.16 \times 10^{-5} B^{2}+1.6 \times 10^{-6} C^{2}
\end{aligned}
$$

where the $A, B$ and $C$ are temperature, $\mathrm{SiO}_{2}$ concentration and SDS concentration, respectively.

Figure 6 presents SDS concentration versus temperature in a constant $\mathrm{SiO}_{2}$ concentration of $1000 \mathrm{ppm}$. The contours show the stability time of solutions (response 1 ). The temperatures in Fig. 6a and b changed from 25 to $45^{\circ} \mathrm{C}$ and 45 to $65^{\circ} \mathrm{C}$, respectively. With increasing SDS concentration from 0 to 1000 ppm in Fig. 6a, the stability changed from 3 to 12 days as the contours show the changes from 2.83 to
11.98. Thus, the surfactant is highly effective on the stability rise. However, in Fig. 6b, when the surfactant concentration was increased to $1000 \mathrm{ppm}$, the stability increased from 1 to 3 days as the contours show the changes from 0.57 to 2.83. Therefore, the surfactant has a weak effect on the stability. Hence, as observed in Fig. $6 a$ and b, the effect of SDS concentration on the solution stability decreases as the temperature increases. The comparison of the stability of solutions 13 and 14 both of which have 3 day stability shows that the main role in the solution stability is played by the $\mathrm{SiO}_{2}$ concentration. As a result, the SDS surfactant could not cause proper stability for silica nanoparticles in temperatures above $45^{\circ} \mathrm{C}$ unless delicate concentrations were used such as the solution 19 in Table 4. 


\subsection{Flooding tests}

\subsubsection{Recovery factor results and temperature effect}

Considering the ultimate recovery factors of tests $1,3,5$ and 7 listed in Table 4 , all of which were flooded at $35^{\circ} \mathrm{C}$, although the $\mathrm{SiO}_{2}$ concentration, SDS concentration and both concentrations were tripled in solutions 3, 5 and 7, respectively, and in comparison with solution 1 , the solution 1 gave the highest recovery factor. Thus, the increases in nanoparticle and surfactant concentrations reduced the recovery factor and increasing nanoparticle concentration has clearly been by far more effective on the recovery factor compared with an increase in SDS concentration.

Comparison of the recovery factors of tests 13 and 14 in which the surfactant concentration changed from zero to $1000 \mathrm{ppm}$ shows that the dominant mechanism, without considering the temperature and at constant nanoparticle concentration, is IFT decrease for oil recovery. Actually, decreasing IFT between the oil and the injected fluid helps the remaining oil to separate from pore walls and channels.

Regarding the ultimate recovery factors of tests 2, 4, 6 and 8 listed in Table 4 , all of which were flooded at $55^{\circ} \mathrm{C}$, the $\mathrm{SiO}_{2}$ concentration of test 4 and the SDS concentration of solution 6 were tripled in comparison with solution 2 . However, the recovery factor of solution 4 was almost equal to that of solution 2 and the recovery factor of solution 6 was almost $14 \%$ less than that of solution 2 . Therefore, an increase in the $\mathrm{SiO}_{2}$ concentration has no effect on the oil recovery factor. Nevertheless, the SDS concentration has a significant effect such that the recovery factor decreased remarkably with an increase in the surfactant concentration, whereas an increase in the nanoparticle concentration decreased the oil recovery factor, as previously indicated in $35{ }^{\circ} \mathrm{C}$-flooding tests.

The temperature difference was $20^{\circ} \mathrm{C}$ in all four pairs of tests $(1,2),(3,4),(5,6)$ and $(7,8)$ in which the ultimate oil recovery differences were $19.6 \%, 26.4 \%, 7.9 \%$ and $7.5 \%$, respectively. In test pairs in which the SDS concentration was equal to $250 \mathrm{ppm}$ (tests $(1,2)$ and tests $(3,4)$ ), the recovery factor difference was much higher than those with the SDS concentrations of $750 \mathrm{ppm}$ (tests $(5,6)$ and $(7,8)$ ). Therefore, it seems that the surfactant concentration plays a major role as the temperature increases. For example, the SDS concentration of test pair $(5,6)$ was tripled in comparison with test pair $(1,2)$, but the recovery factor difference of tests $(1,2)$ was almost 2.5 times more than that of tests $(5$, $6)$. In addition, considering test pairs $(1,2)$ and $(3,4)$, the recovery factor difference of test $(3,4)$ was about $7 \%$ higher than that of tests $(1,2)$. Given that the surfactant concentration in both test pairs was $250 \mathrm{ppm}$ and the nanoparticle

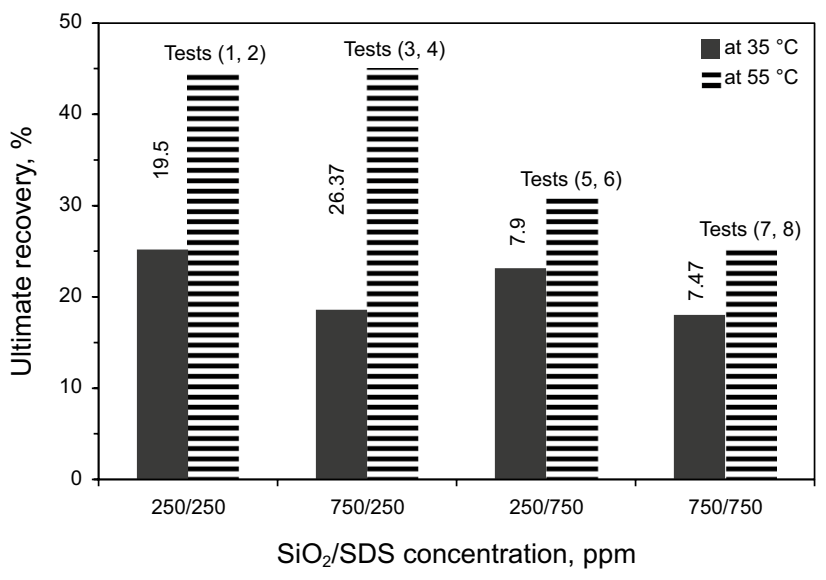

Fig. 7 Ultimate oil recovery of pair tests $(1,2),(3,4),(5,6)$ and $(7,8)$

concentration of tests $(3,4)$ was triple that in tests $(1,2)$, and a positive impact of nanoparticles on the recovery factor is found as the temperature increases. Moreover, in tests $(7,8)$, the nanoparticle concentration was triple that in tests $(5,6)$ and the SDS concentration was equal in both pairs of tests while the recovery factor difference of tests $(5,6)$ and $(7,8)$ almost equaled. As a result, at lower SDS concentrations, increasing the temperature and the nanoparticle concentration could be useful to enhance the oil recovery. However, increasing the temperature and $\mathrm{SiO}_{2}$ concentration with SDS concentration rise has very little effect on oil recovery and is not economical. Figure 7 shows the ultimate oil recovery difference of tests pairs $(1,2),(3,4),(5,6)$ and $(7,8)$.

\subsubsection{Macroscopic and microscopic investigations}

Figure $8 \mathrm{a}-\mathrm{d}$ presents macroscopic and microscopic pictures of tests $1,3,5$ and 7 , which were flooded at $35^{\circ} \mathrm{C}$. As observed in Fig. 8, none of the tests enjoy proper sweep efficiency. In Fig. 8a, oil was appropriately removed from the pore walls by solution 1 , unlike other solutions. In microscopic pictures, the difference in the thickness of the remaining oil layer on pore walls is illustrated clearly. For example, Fig. $8 \mathrm{a}$, which corresponds to test 1 , shows that solution 1 has removed oil from pore walls to a greater degree than other solutions. The low contact angle of solution 1 (Sect. 3.4) also shows the good performance of solution 1 in the removal of oil. Essentially, wettability not only plays a major role in controlling the location, flow and distribution of oil and water phases, but it also affects the relative permeability of a porous medium. Macroscopic and microscopic pictures of tests $2,4,6$ and 8 flooded at $55^{\circ} \mathrm{C}$ are presented in Fig. 9a-d, respectively. Oil sweep efficiencies in tests 2 and 4 (Fig. 9a and b) were higher than those in tests 6 and 

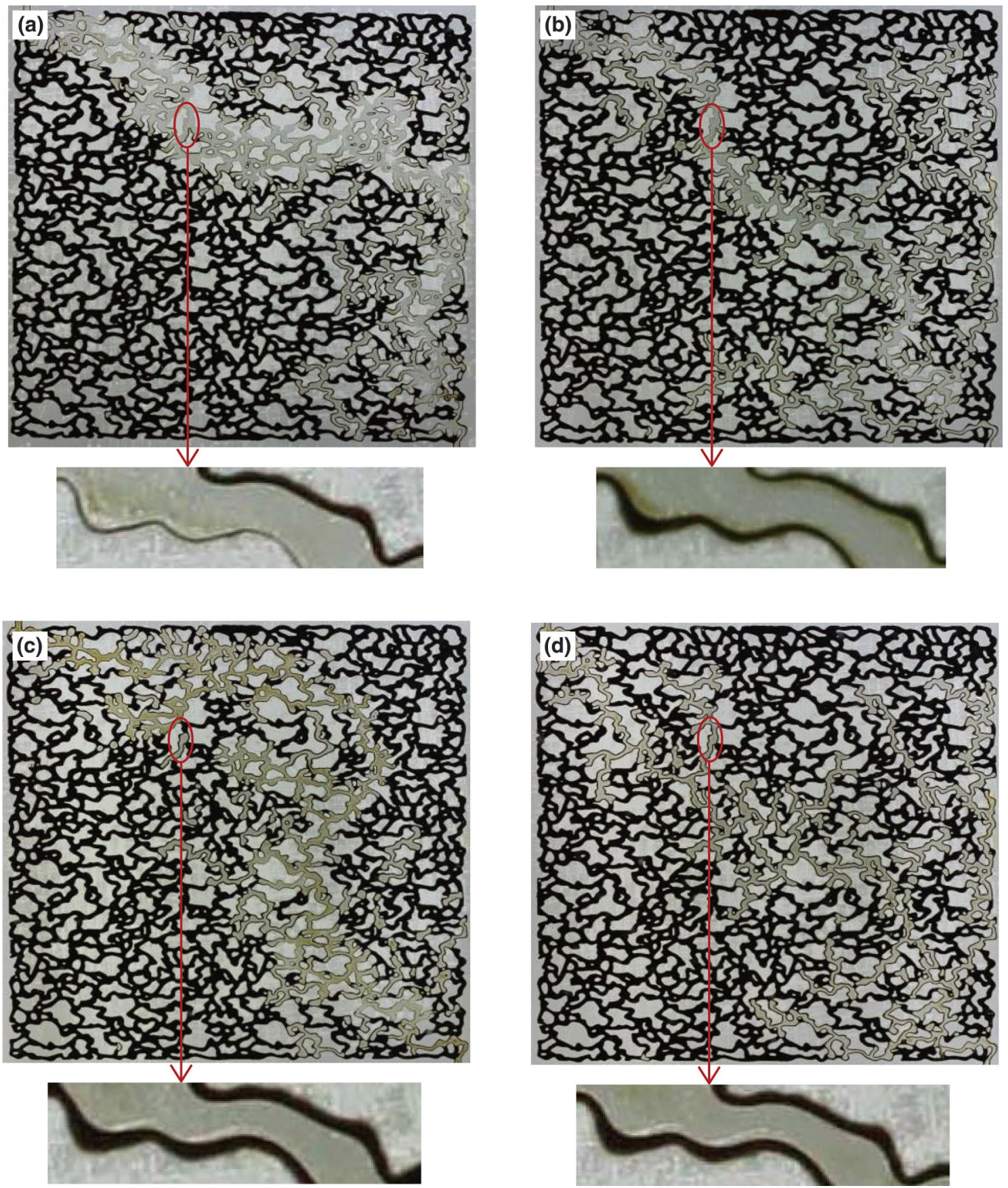

Fig. 8 Macroscopic and microscopic pictures of tests 1 (a), 3 (b), 5 (c) and 7 (d) after injecting 1 PV

8 (Fig. 9c and d). In addition, the small thickness of the remaining oil layer on pore walls in tests 2 and 4 is shown in the microscopic pictures of Fig. 9a and b. The comparison of Figs. 8 and 9 in the tests in which the SDS concentration was $250 \mathrm{ppm}$ shows that increasing the temperature and $\mathrm{SiO}_{2}$ concentration may be effective and strongly enhances the ultimate oil recovery.

\subsubsection{Statistical analysis}

Analysis of variance for response 2 (ultimate recovery) is illustrated in Table 6. Given that the confidence level was $95 \%$, the source $B^{2}$ was excluded from the model to reduce the $p$ value to less than 0.05 . The $R^{2}$ calculated by the software was about 0.76 . According to Table 5, temperature 

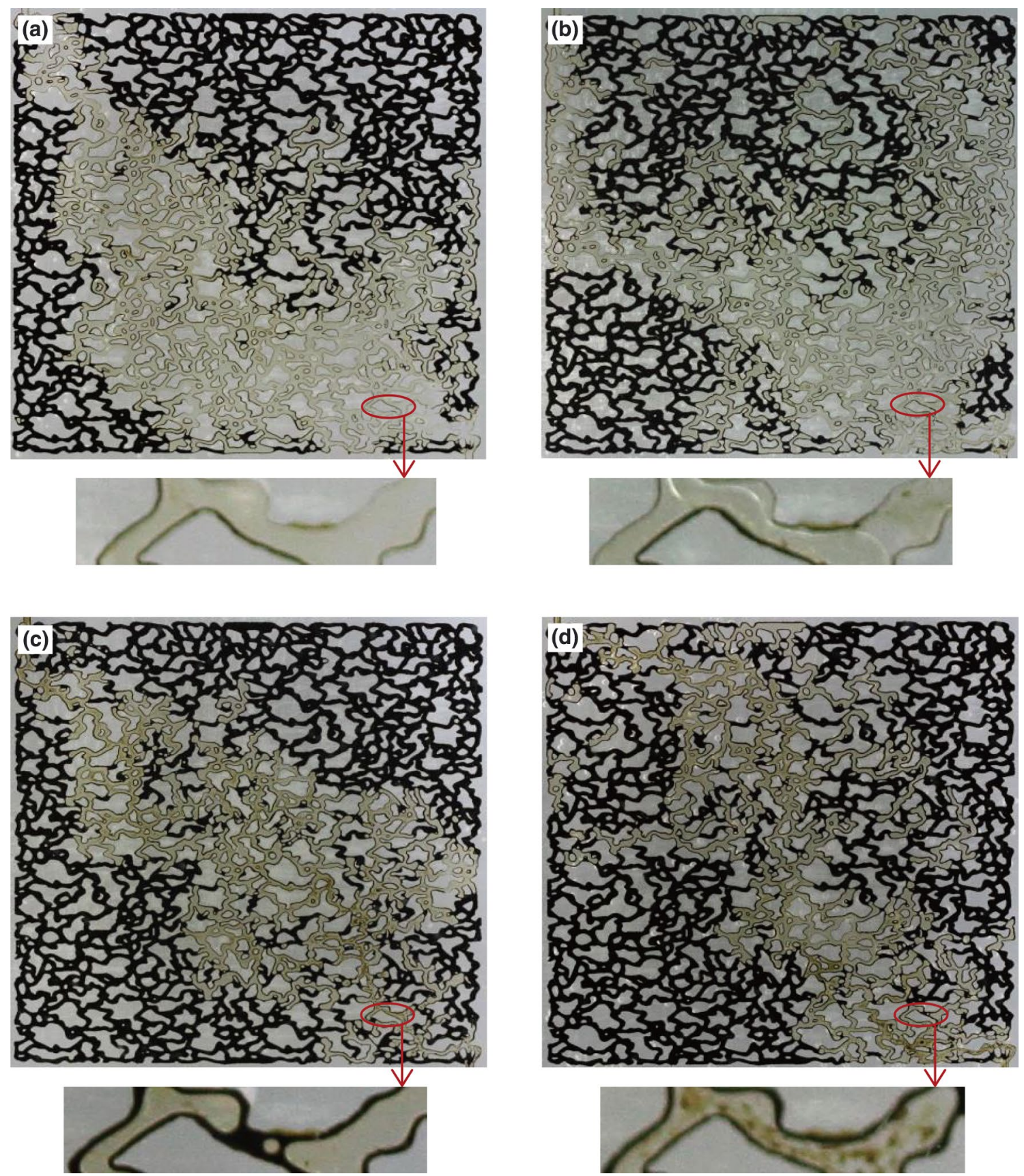

Fig. 9 Macroscopic and microscopic pictures of tests 2 (a), 4 (b), 6 (c) and 8 (d) after injecting 1 PV

(factor $A$ ) has the most impact on the recovery factor followed by temperature-surfactant interaction and nanoparticle concentration (factor $B$ ). It is important to note that temperature-surfactant interaction or temperature impact on SDS behavior in different concentrations is much more effective than the surfactant concentration, as previously discussed in Sects. 3.2.1 and 3.2.2. The suggested model in terms of actual factors is presented by the following equation:

$$
\begin{aligned}
\text { Recovery }= & -57.77041+2.31732 A-0.013245 B \\
& +0.11417 C+3.185 \times 10^{-4} A B \\
& -1.5275 \times 10^{-3} A C-8.54 \times 10^{-6} B C \\
& -0.011765 A^{2}-4.32245 \times 10^{-5} C^{2}
\end{aligned}
$$

where $A, B$ and $C$ are temperature, $\mathrm{SiO}_{2}$ concentration and SDS concentration, respectively. 
Table 6 ANOVA for recovery response

\begin{tabular}{|c|c|c|c|c|c|}
\hline Source & Sum of squares & df & Mean square & $F$ value & $p$ value \\
\hline Model & 1006.87 & 8 & 125.85 & 3.53 & 0.0388 \\
\hline$A$ : temperature & 684.21 & 1 & 684.21 & 19.20 & 0.0018 \\
\hline$B$ : nanoparticle concentration & 10.12 & 1 & 10.12 & 0.28 & 0.6068 \\
\hline$C:$ surfactant concentration & 4.25 & 1 & 4.25 & 0.11 & 0.7376 \\
\hline$A B$ & 5.07 & 1 & 5.07 & 0.14 & 0.7146 \\
\hline$A C$ & 116.66 & 1 & 116.66 & 3.27 & 0.1038 \\
\hline$B C$ & 2.27 & 1 & 2.27 & 0.06 & 0.8060 \\
\hline$A^{2}$ & 33.60 & 1 & 33.60 & 0.94 & 0.3568 \\
\hline$C^{2}$ & 177.17 & 1 & 177.17 & 4.97 & 0.0527 \\
\hline Residual & 320.55 & 9 & 35.617 & & \\
\hline Lack of fit & 308.88 & 6 & 51.48 & 13.23 & 0.0291 \\
\hline Pure error & 11.67 & 3 & 3.89 & & \\
\hline Cor total & 1327.43 & 17 & & & \\
\hline
\end{tabular}
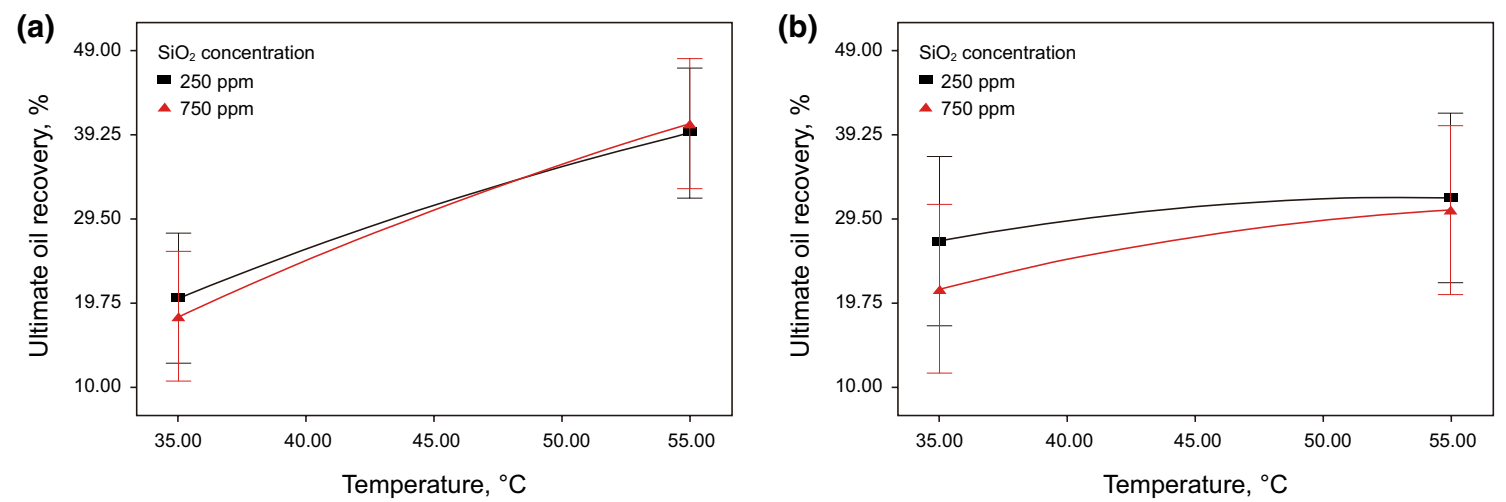

Fig. 10 Ultimate oil recovery versus temperature at nanoparticle concentration of 250 and $750 \mathrm{ppm}$. a SDS concentration of $250 \mathrm{ppm}$. b SDS concentration of $750 \mathrm{ppm}$

Table 7 The viscosity of injected fluids

\begin{tabular}{lll}
\hline Solution No. & $\begin{array}{l}\mathrm{SiO}_{2} / \text { SDS concentrations, } \\
\text { ppm }\end{array}$ & $\begin{array}{l}\text { Viscos- } \\
\text { ity, } \\
\mathrm{mPa} \mathrm{s}\end{array}$ \\
\hline $1 \& 2$ & $250 / 250$ & 3.0 \\
$3 \& 4$ & $750 / 250$ & 5.6 \\
$5 \& 6$ & $250 / 750$ & 3.8 \\
$7 \& 8$ & $750 / 750$ & 5.8 \\
$9,10,15-18$ & $500 / 500$ & 4.8 \\
11 & $0 / 500$ & 2.8 \\
12 & $1000 / 500$ & 6.4 \\
13 & $500 / 0$ & 3.8 \\
14 & $500 / 1000$ & 5.4 \\
\hline
\end{tabular}

The recovery factor versus temperature at an SDS concentration of $250 \mathrm{ppm}$ and different nanoparticle concentrations (250 and $750 \mathrm{ppm}$ ) is shown in Fig. 10a. In Fig. 10b

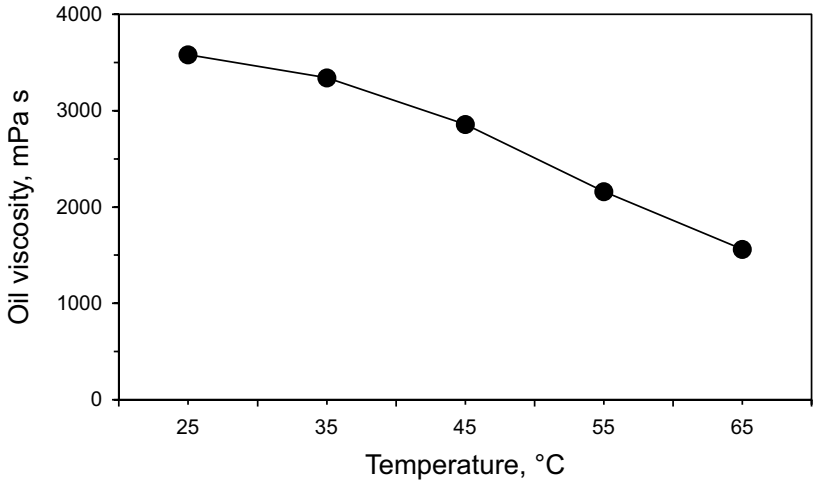

Fig. 11 Oil viscosities at different temperatures

similar to Fig. 10a, the SDS concentration is constant at $750 \mathrm{ppm}$. When the surfactant concentration is equal to $250 \mathrm{ppm}$, increasing the temperature from 35 to $55^{\circ} \mathrm{C}$ and the nanoparticle concentration from 250 to $750 \mathrm{ppm}$ could 


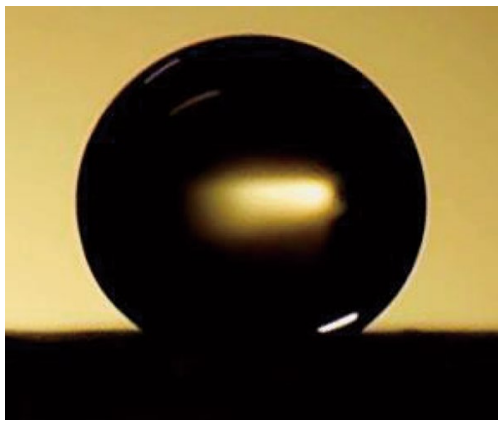

Fig. 12 Water droplet on the glass surface

enhance the recovery factor by about $20 \%$ (Fig. 10a). When the surfactant concentration is equal to $750 \mathrm{ppm}$, a $20{ }^{\circ} \mathrm{C}$ increase in the temperature and three times increase in $\mathrm{SiO}_{2}$ concentration could enhance the recovery factor only by about 7\% (Fig. 10b). In addition, a comparison of slopes of Fig. 10a, b indicates that increasing the porous medium temperature may improve the impact of nanoparticles on enhancing oil recovery. In the other words, as the nanoparticle concentration increases, increasing the temperature could help improve the nanoparticle performance in enhancing oil recovery.

\subsection{Viscosity results}

Table 7 presents the viscosities of the injected fluid at $25^{\circ} \mathrm{C}$, and Fig. 11 shows the oil viscosity at the porous medium temperatures at which the floodings were performed, i.e., $25,35,45,55$ and $65^{\circ} \mathrm{C}$. The results of viscosity shown in Table 7 suggest that the viscosities of the injected fluid were enhanced as both $\mathrm{SiO}_{2}$ and SDS concentrations increased. As the nanoparticle concentration increased, silica particles had more interactions, and a more interconnected threedimensional network was formed. Therefore, the solution viscosity increased. Furthermore, as the surfactant concentration increased, micelles were formed, and the solution viscosity was enhanced. A positive impact of using nanoparticle and surfactant simultaneously on solution viscosity is seen by comparison of the viscosity of solutions 9, 11 and 13. The oil viscosity is expected to decrease with temperature, as shown in Fig. 11.

\subsection{Contact angles}

Figure 12 shows a water drop on a glass surface whose wettability was altered to oil-wet. The measured contact angle was $140^{\circ}$ on average, indicating that the glass was strongly
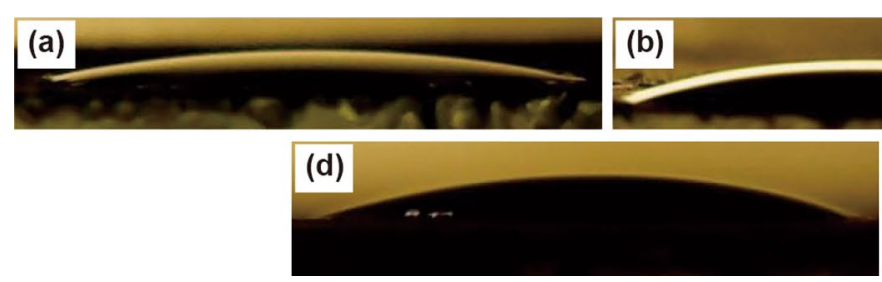
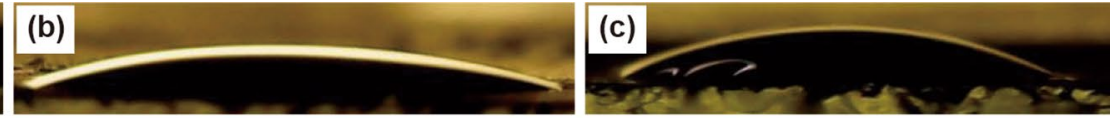

(e)

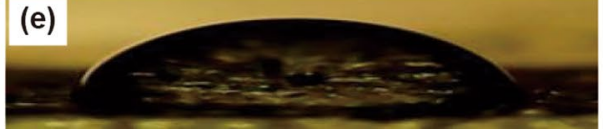

Fig. 13 Measured contact angles between glass and water drop after aging the glass in solution 1 (a), solution 11 (b), solution 13 (c), solution 19 (d) and solution 21 (e)

Table 8 IFT between solutions and oil

\begin{tabular}{|c|c|c|c|c|}
\hline Test No. & $\mathrm{SiO}_{2} / \mathrm{SDS}$ concentrations, ppm & Maximum force $F, \mathrm{mg}$ & Correction factor $f$ & $\begin{array}{l}\text { Interfacial tension, } \\
\mathrm{mN} / \mathrm{m}\end{array}$ \\
\hline $1 \& 2$ & $250 / 250$ & 17.5 & 0.826 & 1.182 \\
\hline $3 \& 4$ & $750 / 250$ & 14.0 & 0.826 & 0.945 \\
\hline $5 \& 6$ & $250 / 750$ & 14.3 & 0.826 & 0.966 \\
\hline $7 \& 8$ & $750 / 750$ & 13.3 & 0.826 & 0.898 \\
\hline \multirow[t]{2}{*}{$9,10,15$ to 18} & $500 / 500$ & $20.2 @ 25^{\circ} \mathrm{C}$ & 0.826 & 1.364 \\
\hline & & $13.6 @ 65^{\circ} \mathrm{C}$ & 0.826 & 0.918 \\
\hline 11 & $0 / 500$ & 15.5 & 0.826 & 1.047 \\
\hline 12 & $1000 / 500$ & 14.2 & 0.826 & 0.959 \\
\hline 13 & $500 / 0$ & 239.3 & 0.827 & 16.178 \\
\hline 14 & $500 / 1000$ & 15.2 & 0.826 & 1.026 \\
\hline 21 & $0 / 0$ & 211.6 & 0.827 & 14.306 \\
\hline
\end{tabular}


oil-wet. The measured contact angles for Fig. 13a-e, corresponding to solutions 1 (or 2), 11,13 and 21 , were equal to $12^{\circ}, 16^{\circ}, 32^{\circ}, 18^{\circ}$ and $81^{\circ}$, respectively. The nanoparticles and surfactant added to the solutions strongly alter the glass wettability to water-wet simultaneously. The effect of the surfactant on changing wettability is stronger than that of the nanoparticles because the contact angle of solution 11 is less than that of solution 13 (Fig. 13b and c). The contact angle corresponding to solution 21 ( $\mathrm{NaCl}$ solution), Fig. $13 \mathrm{e}$, shows that the $\mathrm{NaCl}$ salt itself could reduce the contact angle.

\subsection{IFT}

Table 8 presents IFT values between injected solutions and oil. In order to investigate the effect of temperature on IFT, IFTs between oil and the solution with $\mathrm{SiO}_{2} / \mathrm{SDS}$ concentrations of 500/500 ppm were measured at 25 and $65{ }^{\circ} \mathrm{C}$, respectively. It was observed that the temperature had only a slight effect on IFT because just a small change in IFT was observed with a temperature increase of $40{ }^{\circ} \mathrm{C}$. The IFT between solution $13\left(500 \mathrm{ppm} \mathrm{SiO}_{2}\right)$ and oil was higher than that between solution $21\left(0 \mathrm{ppm} \mathrm{SiO}_{2}\right)$ and oil. Therefore, the nanoparticles could increase the IFT. The total free energy tends to adsorb nanoparticles at the liquid interface; in addition to this, the formation of an electrical double layer on particle surfaces results in more hydrophobic particles which tend toward the interface. Consequently, the particles migrate from the water phase to the oil-water interface. The particles which migrate to the interface cause the interface to deform. Lateral capillary forces then develop, and IFT increases. Nevertheless, when the nanoparticle/surfactant solutions were used, the IFT decreased even more compared with the SDS solution (solution 11). Nanoparticles can adsorb surfactants and carry them to the interface as carriers of SDS. Therefore, the number of the surfactant monomers at the interface increases and the IFT is reduced more. With regarding to the process that made solutions more stable, it can be concluded that the more stable the solution is, the lower the IFT will be and the oil recovery increases. Considering all calculated IFTs in Table 8, apart from tests 13 and 21 , changing concentrations of $\mathrm{SiO}_{2}$ and SDS in the scale
Table 10 Sandpack flooding test results

\begin{tabular}{lllll}
\hline $\begin{array}{l}\text { Sandpack } \\
\text { porosity, } \%\end{array}$ & $\begin{array}{l}\text { Sandpack } \\
\text { permeabil- } \\
\text { ity, mD }\end{array}$ & Chemical formula & $\begin{array}{l}\text { Salinity, } \\
\text { ppm }\end{array}$ & $\begin{array}{l}\text { Oil } \\
\text { recovery, } \\
\%\end{array}$ \\
\hline 24.6 & 1060 & $\begin{array}{l}500 \mathrm{ppm} \\
\mathrm{SiO}_{2}+500 \mathrm{ppm} \\
\mathrm{SDS}\end{array}$ & 35,000 & 31.8 \\
& & \\
\hline
\end{tabular}

of hundreds of ppm do not have a great effect on increasing or decreasing IFT.

\subsection{Optimization and confirmation tests}

Tests 19 and 20 whose stability and ultimate recovery are listed in Table 3 are the confirmation tests for the optimization suggested by the software. Table 9 presents the results of optimization tests and the corresponding confirmation tests. It should be noted that the target of optimization is to maximize the responses. The obtained responses for both tests 19 and 20 are in good agreement with the predicted values at a 95\% confidence level and confirmed the model.

\subsection{Sandpack flood test}

The sandpack flood results illustrated in Table 10 indicate that the ultimate oil recovery was $31.8 \%$ after nanoparticle/surfactant flooding. This is satisfactory compared to the micromodel oil recoveries of tests $15-18$, which were 33.5\% on average. The oil recovery from the sandpack, which is an indication of a more real example of reservoir conditions, shows the concentrations used in the micromodel floodings could lead to satisfactory recoveries even if the concentrations are low.

\section{Conclusions}

To investigate the temperature effect on the fluid stability and performance of nanoparticle/surfactant fluids used for enhanced heavy oil recovery, many tests were designed and performed using the software based on CCD method to

Table 9 Predicted and experimental responses under optimum conditions

\begin{tabular}{|c|c|c|c|c|c|c|}
\hline \multirow{2}{*}{$\begin{array}{l}\text { Temperature, } \\
{ }^{\circ} \mathrm{C}\end{array}$} & \multirow{2}{*}{$\begin{array}{l}\text { Nanoparticle concen- } \\
\text { tration, ppm }\end{array}$} & \multirow{2}{*}{$\begin{array}{l}\text { Surfactant concentra- } \\
\text { tion, ppm }\end{array}$} & \multicolumn{2}{|c|}{ Predicted responses } & \multicolumn{2}{|c|}{ Confirmation test } \\
\hline & & & Stability, days & $\begin{array}{l}\text { Ultimate recov- } \\
\text { ery, } \%\end{array}$ & Stability, days & $\begin{array}{l}\text { Ultimate } \\
\text { recovery, } \\
\%\end{array}$ \\
\hline 65 & 45.81 & 158.59 & 20 & 44.69 & 20 & 42.12 \\
\hline 65 & 133.67 & 192.85 & - & 45.06 & - & 44.17 \\
\hline
\end{tabular}


determine stability, viscosity, contact angle, IFT and recovery factor of the solutions. The following conclusions are drawn.

1. $\mathrm{NaCl}$ decreases the stability of silica nanoparticle solutions, but the surfactant SDS increases it. At higher temperatures, the role of the surfactant concentration becomes much more important; that is, inappropriate surfactant concentrations can even decrease the solution stability. Based on the model suggested by the software, the nanoparticle concentration is the most effective factor affecting the solution stability, followed by temperature. Increasing temperature not only results in solution instability, but also decreases the positive effect of the surfactant.

2. The viscosity results indicate that changing the concentration of the surfactant and nanoparticle from 0 to $1000 \mathrm{ppm}$ does not change the viscosity much. The oil viscosity is almost halved when the temperature is raised from 25 to $65^{\circ} \mathrm{C}$.

3. The contact angle results demonstrate that for altering the glass wettability the $\mathrm{SiO}_{2} / \mathrm{SDS}$ solution is the most effective, followed by the SDS solution and the $\mathrm{SiO}_{2}$ solution.

4. The IFT results show the $\mathrm{SiO}_{2}$ nanoparticles alone raise the IFT while the $\mathrm{SiO}_{2} / \mathrm{SDS}$ solution decreases IFT even more than the SDS solution.

5. The ultimate oil recovery factor results indicate that increasing temperature and nanoparticle concentration significantly enhances the oil recovery when the surfactant concentration is $250 \mathrm{ppm}$, but increases in temperature and nanoparticle concentration have a little effect on the oil recovery factor when the surfactant concentration is $750 \mathrm{ppm}$. According to the model suggested by the software, the temperature and temperature-surfactant interaction are the most effective factors in response 2, ultimate oil recovery. In addition, as the nanoparticle concentration increases, increasing the temperature may improve the performance of nanoparticles in enhancing oil recovery.

6. Recovery factors obtained from the optimization tests, 19 and 20 , respectively, are $16.6 \%$ and $18.9 \%$ more than those obtained from solution 21 , which only contains $\mathrm{NaCl}$. Therefore, the optimum concentrations suggested by the software remarkably enhance the ultimate oil recovery.

Acknowledgements This work is financially supported by the Iran Nanotechnology Initiative Council.
Open Access This article is distributed under the terms of the Creative Commons Attribution 4.0 International License (http://creativeco mmons.org/licenses/by/4.0/), which permits unrestricted use, distribution, and reproduction in any medium, provided you give appropriate credit to the original author(s) and the source, provide a link to the Creative Commons license, and indicate if changes were made.

\section{References}

Ahmadi MA, Shadizadeh SR. Induced effect of adding nano silica on adsorption of a natural surfactant onto sandstone rock: experimental and theoretical study. J Pet Sci Eng. 2013;112:239-47. https:// doi.org/10.1016/j.petrol.2013.11.010.

Alomair OA, Matar KM, Alsaeed YH. Nanofluids application for heavy oil recovery. In: SPE Asia Pacific Oil \& Gas Conference and Exhibition; 2014: Society of Petroleum Engineers. https://doi. org/10.2118/171539-MS.

Arshadi M, Mousavi SM. Enhancement of simultaneous gold and copper extraction from computer printed circuit boards using Bacillus megaterium. Biores Technol. 2015;175:315-24. https://doi. org/10.1016/j.biortech.2014.10.083.

Bera A, Belhaj H. Application of nanotechnology by means of nanoparticles and nanodispersions in oil recovery: a comprehensive review. J Nat Gas Sci Eng. 2016;34:1284-309. https://doi. org/10.1016/j.jngse.2016.08.023.

Butt H-J, Graf K, Kappl M. Physics and Chemistry of Interfaces. Hoboken: Wiley-VCH Verlag GmbH \& Co. KGaA; 2004.

Cifuentes A, Bernal JL, Diez-Masa JC. Determination of critical micelle concentration values using capillary electrophoresis instrumentation. Anal Chem. 1997;69(20):4271-4. https://doi. org/10.1021/ac970696n.

Daoshan L, Shouliang L, Yi L, Demin W. The effect of biosurfactant on the interfacial tension and adsorption loss of surfactant in ASP flooding. Colloids Surf A. 2004;244(1):53-60. https://doi. org/10.1016/j.colsurfa.2004.06.017.

Drelich J, Fang C, White C. Measurement of interfacial tension in fluid-fluid systems. Encycl Surf Colloid Sci. 2002;3:3158-63.

Emami Meybodi H, Kharrat R, Wang X. Study of microscopic and macroscopic displacement behaviors of polymer solution in waterwet and oil-wet media. Transp Porous Media. 2011;89(1):97-120. https://doi.org/10.1007/s11242-011-9754-5.

Esmaeilzadeh P, Hosseinpour N, Bahramian A, Fakhroueian Z, Arya S. Effect of $\mathrm{ZrO}_{2}$ nanoparticles on the interfacial behavior of surfactant solutions at air-water and n-heptane-water interfaces. Fluid Phase Equilib. 2014;361:289-95. https://doi.org/10.1016/j. fluid.2013.11.014.

Gunnasegaran P, Abdullah MZ, Yusoff MZ, Abdullah SF. Optimization of $\mathrm{SiO}_{2}$ nanoparticle mass concentration and heat input on a loop heat pipe. Case Studies Thermal Eng. 2015;6:238-50. https://doi. org/10.1016/j.csite.2015.10.004.

Hamedi Shokrlu Y, Babadagli T. Effects of nano-sized metals on viscosity reduction of heavy oil/bitumen during thermal applications. In: Canadian Unconventional Resources and International Petroleum Conference; 2010: Society of Petroleum Engineers. https:// doi.org/10.2118/137540-MS.

Hendraningrat L, Li S, Torsater O. Effect of some parameters influencing enhanced oil recovery process using silica nanoparticles: an experimental investigation. In: SPE Reservoir Characterization and Simulation Conference and Exhibition; 2013; Society of Petroleum Engineers. https://doi.org/10.2118/165955-MS. 
Howe AM, Clarke A, Mitchell J, Staniland J, Hawkes LA. Visualising surfactant EOR in core plugs and micromodels. In: SPE Asia Pacific Enhanced Oil Recovery Conference; 2015. Society of Petroleum Engineers. https://doi.org/10.2118/174643-MS.

Iglauer S, Wu Y, Shuler P, Tang Y, Goddard WA III. New surfactant classes for enhanced oil recovery and their tertiary oil recovery potential. J Petrol Sci Eng. 2010;71(1-2):23-9. https://doi. org/10.1016/j.petrol.2009.12.009.

Javadian S, Yousefi A, Neshati J. Synergistic effect of mixed cationic and anionic surfactants on the corrosion inhibitor behavior of mild steel in NaCl. Appl Surf Sci. 2013;285:674-81. https://doi. org/10.1016/j.apsusc.2013.08.109.

Kianinejad A, Ghazanfari MH, Kharrat R, Rashtchian D. An experimental investigation of surfactant flooding as a good candidate for enhancing oil recovery from fractured reservoirs using one-quarter five spot micromodels: the role of fracture geometrical properties. Energy Sour Part A Recovery Util Environ Effects. 2013;35(20):1929-38. https://doi.org/10.1080/15567 036.2010.525591.

Kianinejad A, Rashtchian D, Ghazanfari MH, Kharrat R. A porelevel investigation of surfactant-crude oil displacements behavior in fractured porous media using one-quarter five spot micromodels. Energy Sour Part A Recovery Util Environ Effects. 2014;36(7):727-37. https://doi.org/10.1080/15567 036.2010.540632.

Kumar N, Mandal A. Surfactant stabilized oil-in-water nanoemulsion: stability, interfacial tension, and rheology study for enhanced oil recovery application. Energy Fuels. 2018;32(6):6452-66. https:// doi.org/10.1021/acs.energyfuels.8b00043.

Lan Q, Yang F, Zhang S, Liu S, Xu J, Sun D. Synergistic effect of silica nanoparticle and cetyltrimethyl ammonium bromide on the stabilization of O/W emulsions. Colloids Surf A. 2007;302(13):126-35. https://doi.org/10.1016/j.colsurfa.2007.02.010.

Lohne A, Fjelde I. Surfactant flooding in heterogeneous formations. In: SPE Improved Oil Recovery Symposium; 2012. Society of Petroleum Engineers. https://doi.org/10.2118/154178-MS.

Ma H, Luo M, Dai LL. Influences of surfactant and nanoparticle assembly on effective interfacial tensions. Phys Chem Chem Phys. 2008;10(16):2207-13. https://doi.org/10.1039/b718427c.

Maghzi A, Mohebbi A, Kharrat R, Ghazanfari MH. Pore-scale monitoring of wettability alteration by silica nanoparticles during polymer flooding to heavy oil in a five-spot glass micromodel. Transp Porous Media. 2010;87(3):653-64. https://doi.org/10.1007/s1124 2-010-9696-3.

Mai A, Bryan J, Goodarzi N, Kantzas A. Insights into non-thermal recovery of heavy oil. J Can Pet Technol. 2009;48(03):27-35. https://doi.org/10.2118/09-03-27.

Maurya NK, Mandal A. Investigation of synergistic effect of nanoparticle and surfactant in macro emulsion based EOR application in oil reservoirs. Chem Eng Res Des. 2018;132:370-84. https://doi. org/10.1016/j.cherd.2018.01.049.

Mohammadi S, Maghzi A, Ghazanfari MH, Masihi M, Mohebbi A, Kharrat R. On the control of glass micro-model characteristics developed by laser technology. Energy Sour Part A Recovery Util Environ Effects. 2013;35(3):193-201. https://doi. org/10.1080/15567036.2010.516325.

Munshi AM, Singh VN, Kumar M, Singh JP. Effect of nanoparticle size on sessile droplet contact angle. J Appl Phys. 2008;103(8):084315. https://doi.org/10.1063/1.2912464.

Nwidee LN, Lebedev M, Barifcani A, Sarmadivaleh M, Iglauer S. Wettability alteration of oil-wet limestone using surfactant-nanoparticle formulation. J Colloid Interf Sci. 2017;504(C):334-45. https://doi.org/10.1016/j.jcis.2017.04.078.

Ogolo N, Olafuyi O, Onyekonwu M, editors. Enhanced oil recovery using nanoparticles. In: SPE Saudi Arabia Section Technical
Symposium and Exhibition; 2012: Society of Petroleum Engineers. https://doi.org/10.2118/160847-MS.

Pei H, Zhang G, Ge J, Zhang J, Zhang Q, Fu L. Investigation of nanoparticle and surfactant stabilized emulsion to enhance oil recovery in waterflooded heavy oil reservoirs. In: SPE Canada Heavy Oil Technical Conference; 2015: Society of Petroleum Engineers. https://doi.org/10.2118/174488-MS.

Pillai P, Kumar A, Mandal A. Mechanistic studies of enhanced oil recovery by imidazolium-based ionic liquids as novel surfactants. J Ind Eng Chem. 2018;63:262-74. https://doi.org/10.1016/j. jiec.2018.02.024.

Qiu F. The potential applications in heavy oil EOR with the nanoparticle and surfactant stabilized solvent-based emulsion. In: Canadian Unconventional Resources and International Petroleum Conference; 2010: Society of Petroleum Engineers. https://doi. org/10.2118/134613-MS.

Seethepalli A, Adibhatla B, Mohanty K. Wettability alteration during surfactant flooding of carbonate reservoirs. In: SPE/DOE Symposium on Improved Oil Recovery; 2004: Society of Petroleum Engineers. https://doi.org/10.2118/89423-MS.

Suleimanov BA, Ismailov FS, Veliyev EF. Nanofluid for enhanced oil recovery. J Pet Sci Eng. 2011;78(2):431-7. https://doi. org/10.1016/j.petrol.2011.06.014.

Sun Q, Li Z, Li S, Jiang L, Wang J, Wang P. Utilization of surfactantstabilized foam for enhanced oil recovery by adding nanoparticles. Energy Fuels. 2014;28(4):2384-94. https://doi.org/10.1021/ef402 453b.

Sun Q, Li Z, Wang J, Li S, Li B, Jiang L, et al. Aqueous foam stabilized by partially hydrophobic nanoparticles in the presence of surfactant. Colloids Surf A. 2015;471:54-64. https://doi. org/10.1016/j.colsurfa.2015.02.007.

Torsater O, Engeset B, Hendraningrat L, Suwarno S. Improved oil recovery by nanofluids flooding: an experimental study. In: SPE Kuwait International Petroleum Conference and Exhibition; 2012: Society of Petroleum Engineers. https://doi.org/10.2118/16333 5-MS.

Vladimir A, Eduardo M. Enhanced Oil Recovery: Field Planning and Development Strategies. Oxford: Gulf Professional Publishing; 2010.

Wu Y, Shuler PJ, Blanco M, Tang Y, Goddard WA. A study of wetting behavior and surfactant EOR in carbonates with model compounds. In: SPE/DOE Symposium on Improved Oil Recovery; 2006: Society of Petroleum Engineers. https://doi. org/10.2118/99612-MS.

Wu Y, Chen W, Dai C, Huang Y, Li H, Zhao M, et al. Reducing surfactant adsorption on rock by silica nanoparticles for enhanced oil recovery. J Pet Sci Eng. 2017;153(Supplement C):283-7. https:// doi.org/10.1016/j.petrol.2017.04.015.

Yadali Jamaloei B, Kharrat R. Analysis of microscopic displacement mechanisms of dilute surfactant flooding in oil-wet and water-wet porous media. Transp Porous Media. 2009;81(1):1-19. https://doi. org/10.1007/s11242-009-9382-5.

Yadali Jamaloei B, Kharrat R, Asghari K, Torabi F. The influence of pore wettability on the microstructure of residual oil in surfactant-enhanced water flooding in heavy oil reservoirs: implications for pore-scale flow characterization. J Petrol Sci Eng. 2011;77(1):121-34. https://doi.org/10.1016/j.petrol.2011.02.013.

Zargartalebi M, Barati N, Kharrat R. Influences of hydrophilic and hydrophobic silica nanoparticles on anionic surfactant properties: interfacial and adsorption behaviors. J Petrol Sci Eng. 2014;119:36-43. https://doi.org/10.1016/j.petrol.2014.04.010.

Zargartalebi M, Kharrat R, Barati N. Enhancement of surfactant flooding performance by the use of silica nanoparticles. Fuel. 2015;143:21-7. https://doi.org/10.1016/j.fuel.2014.11.040. 